\title{
EQUIPMENT DESIGN AND TESTING TRANSFER VOLTAGE REFERRING TO IEC 156 STANDARD USING VIRGIN COCONUT OIL (VCO) WITH OIL TEMPERATURE CONDITIONING
}

\author{
ANSYORI ${ }^{* 1}$, IRSYADI YANI ${ }^{2}$, ERIC RAHMAN ${ }^{1}$ \\ ${ }^{1}$ Dept. of Electrical Engineering, Universitas Sriwijaya, Palembang, Indonesia \\ ${ }^{2}$ Dept. of Mechanical Engineering, Universitas Sriwijaya, Palembang, Indonesia \\ *Corresponding author: ansyori@ft.unsri.ac.id
}

(Received: 3 March 2021; Accepted: 21 June 2021; Published on-line: 1 July 2021)

\begin{abstract}
Isolation is a separator between conductors in electrical equipment that prevents flashover, resulting in a short circuit or electrical failure. Isolation is critical in electrical appliances, exceptionally High Voltage Power Equipment (HVPE), to ensure the safety of circuit breakers, capacitors, and transformers. In addition to being an isolator, the insulating liquid material also serves to cool the heat generated by electrical appliances. Isolator with mineral oil-based transformer has various environmental issues, including nonbiodegradability, non-renewability, and rarity. Because it is environmentally safe and extensively used, virgin coconut oil (VCO) is an alternative transformer oil insulation. This study aims to determine the properties of Virgin Coconut Oil (VCO) breakdown voltage using the IEC 156 standard and oil temperature conditioning. According to the test results, the oil breakdown voltage before heating (at room temperature) is $14 \mathrm{kV}$, which is much below the IEC 156 standard, and the breakdown voltage after heating at $90^{\circ}$ is $35 \mathrm{kV}$, and $110^{\circ}$ is 40 $\mathrm{kV}$, which is even higher than the IEC 156 requirement
\end{abstract}

KEYWORDS: Transformator Insulation, Virgin Coconut Oil, Oil Heating, IEC 156 Standard.

\section{INTRODUCTION}

Insulation acts as a barrier between the voltage conductors in electrical equipment, preventing an electric jump resulting in a Short Connection or electrical failure. Insulation is used in a variety of applications. Insulating materials are classified into three classes based on their physical properties: gas, liquid, and solid. Liquid type insulation is utilized in high voltage electrical equipment such as transformers because it acts as a separator and a cooling material. When applied to high-voltage equipment in the field, if the voltage applied exceeds the dielectric strength of the liquid insulation, a breakdown voltage can occur. Generally, liquid insulation used in transformers is produced from petroleum, such as transformer oil sold under the Nynas and Shell Diala brands [1].

Petroleum is a non-renewable natural resource because its renewal takes a very long time (millions of years). According to National Geographic, in 2009, the amount of crude oil remaining on earth was estimated at around 1.2 trillion barrels. Although many new oil fields are discovered, the current supply is not comparable to the discoveries of these fields. Based on the current picture of consumption, which reaches 87 million barrels per day, it is estimated that 1.2 trillion barrels of oil will run out in 44 years. Furthermore, liquid insulation made from petroleum processing is not suitable for the surrounding environment because the waste is complicated to biodegrade. Therefore, it is necessary to replace liquid insulating materials from 
petroleum with other liquid insulating materials that are environmentally friendly and renewable natural resources.

One type of liquid insulating material that can substitute for petroleum liquid insulation is natural esters which are commonly found in vegetable oils. Vegetable oil is included in renewable natural resources and biodegradable when the oil is no longer used and disposed of into the wild. In addition, vegetable oil also has a high burning point and is very easy to find. In terms of composition, the liquid insulating material in transformer oil derived from petroleum consists of a complex mixture of hydrocarbon molecules containing bound $\mathrm{CH} 3$, $\mathrm{CH} 2$, and $\mathrm{CH}$ molecular groups. In this case, the hydrocarbon molecular bonds are also present in vegetable oils. One type of vegetable oil that can be used as a liquid insulating material is a vegetable oil derived from virgin coconut or Virgin Coconut Oil (VCO). [12]

Based on the description above, a study was carried out to know the level of breakdown of voltage (Breakdown) with Virgin Coconut Oil (VCO. Therefore, it can reference further research related to the feasibility of Virgin Coconut Oil (VCO) as a substitute for liquid insulating materials derived from petroleum. In addition, several tests were carried out regarding the IEC 156 standard.

\section{MATERIALS AND METHOD}

The instrument in this study is designed to create spherical electrodes used in the breakdown voltage test. For the test tank constructed of acrylic, the electrode size is developed with a diameter of $12.7 \mathrm{~mm}$, and the electrode material is steel (according to the IEC 156) standard, as shown in Fig. 1. The distance between the ball electrodes can likewise be varied with spherical electrodes. The design of ball electrodes and test containers used in measuring the breakdown voltage utilizing equipment with an $\mathrm{AC}$ voltage source is shown in the diagram below.

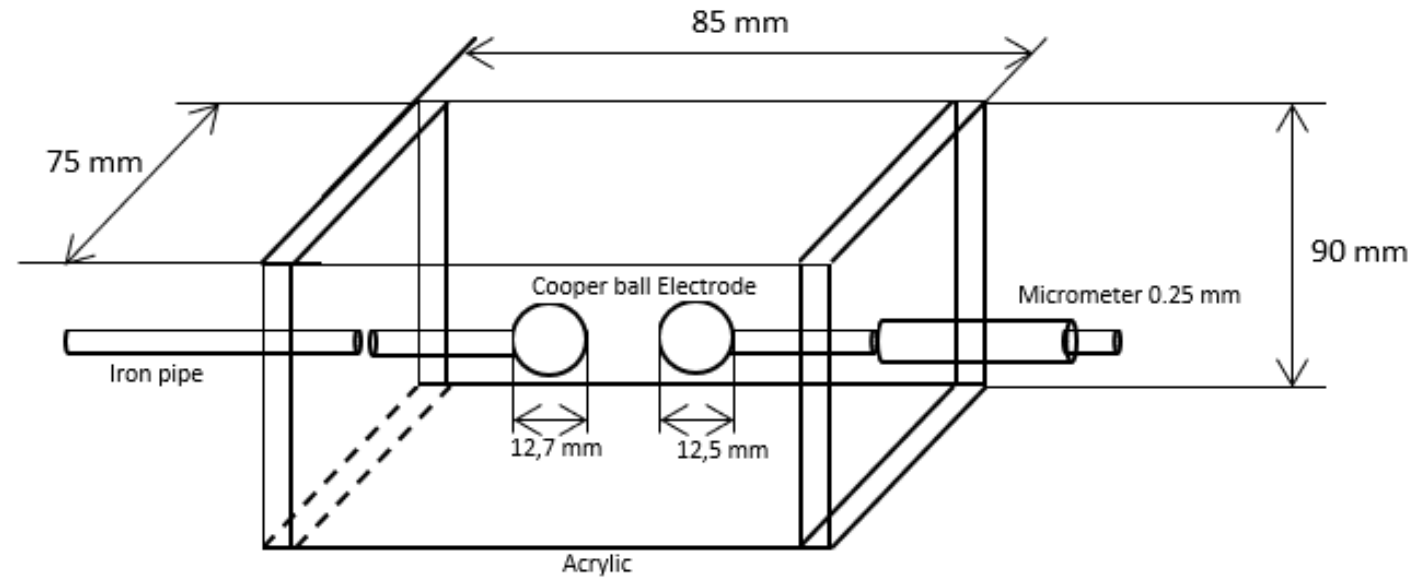

Fig. 1. Testing Vessel

The breakdown voltage tester (Breakdown) operates on the principle that a voltage generator supplies a voltage supply gradually from 0 to $100 \mathrm{kV}$ with an increase of 2.0 $\mathrm{kV} / \mathrm{s}$, at a frequency of $50 \mathrm{~Hz}$, to two electrodes in the test vessel insulating oil separated by a predetermined distance based on the reference standard used. The process of increasing the voltage continues until the electric charge on the two electrodes is fully 
charged, at which point the insulating oil gradually bridges the electrical charge between the two electrodes, resulting in a fast connection.

The value of the voltage at the time of the Short Connection is the value of the breakdown voltage (Breakdown). Then after that, the voltage increase will start again from $0 \mathrm{kV}$ until it reaches the voltage that causes the next Short Connection. The occurrence of a Short Connection like this repeatedly continues until six values of breakdown voltage are obtained.

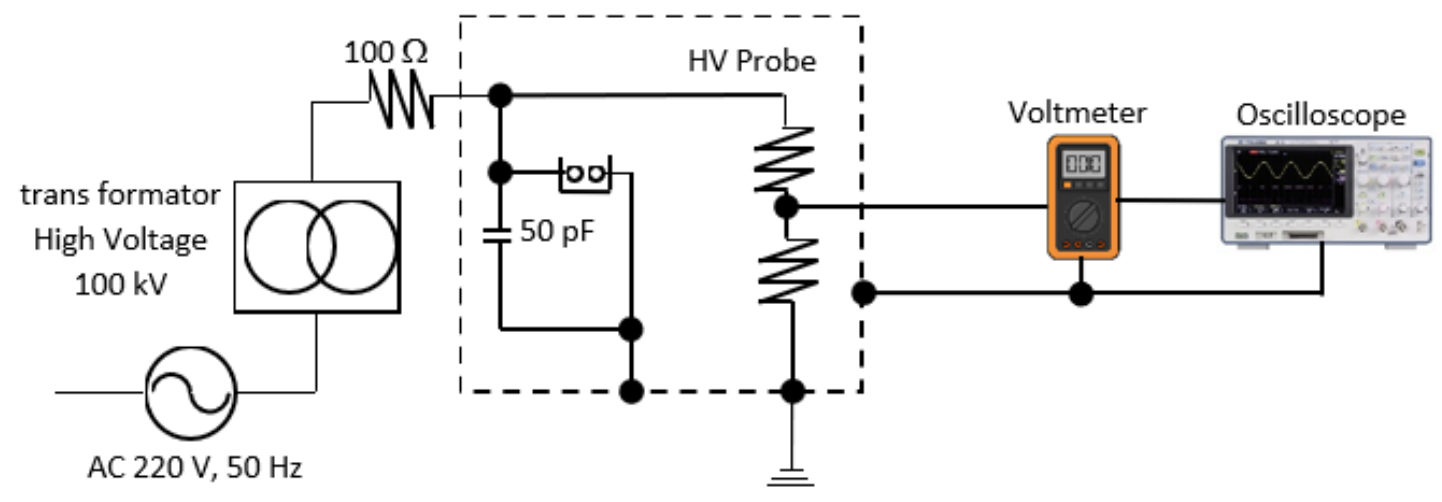

Fig. 2. Breakthrough Voltage Test Circuit

This breakdown voltage test aims to measure the dielectric strength of an insulating oil's capacity to tolerate electric stress. In most cases, insulating oil that is clean and dry will have a high breakdown voltage. However, several factors, including high water content and precipitated particles in the insulating oil, can drastically affect the breakdown voltage. As a result, impurities such as water content and other particles can be detected using this breakdown voltage test. In other words, a low breakdown voltage value can indicate the presence of a small number of contaminants in the insulating oil or even a large number of contaminants. On the other hand, a high breakdown voltage does not necessarily mean that the insulating oil is free of all impurities.

The oil sample used in this investigation was Virgin Coconut Oil (VCO), as shown in Fig. 2. The IEC 60156 standard was used to conduct the breakdown voltage test in this investigation, which was carried out with homemade test equipment.

According to the IEC standard, a ball electrode with a diameter of $12.7 \mathrm{~mm}$ is utilized. Fig. 3 shows the type of each electrode (ball electrode type $12.7 \mathrm{~mm}$ ) when a size of 2.5 $\mathrm{mm}$ is used for the space between the electrodes when the test is performed.

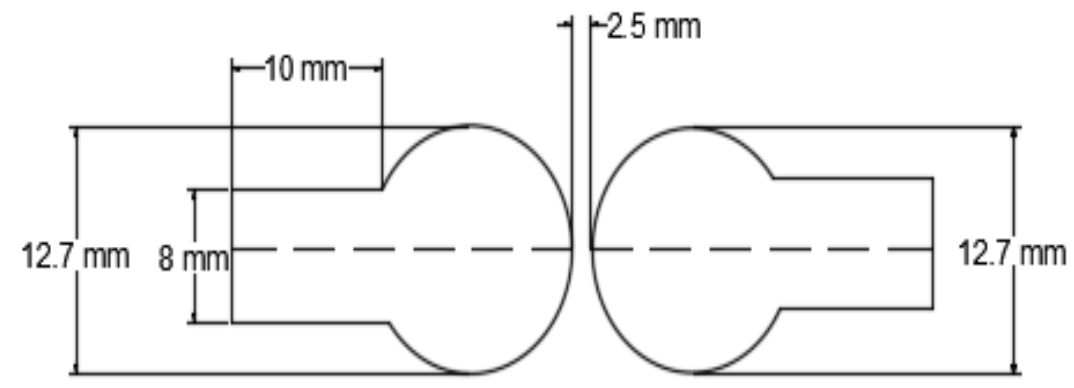

Fig. 3. Ball type electrode $12,7 \mathrm{~mm}$ 
The IEC 60156 standard does the testing of the breakdown voltage (Breakdown). According to the IEC 60156 standard, the electrode type is a $12.7 \mathrm{~mm}$ ball electrode with a $2.5 \mathrm{~mm}$ gap between the electrodes. The steps for checking the breakdown voltage are as follows:

a. Prepare test equipment and Virgin Coconut Oil (VCO) samples, clean the test container with oil samples, and rinse the electrodes used in the test.

b. Fill the test container with the oil sample until it reaches a predetermined size of around $400 \mathrm{ml}$, then ensure the electrode is submerged in the oil sample. Next, start the test with a $6 \mathrm{x}$ BdV test.

c. Start the test with a $6 \mathrm{x} B d V$ test

d. Clean up all of the equipment and test equipment after all of the appropriate tests have been done. For example, before storing the oil sample, remove it from the test container and clean it.

The operational temperature limit below which the insulating oil begins to burn is known as the flashpoint. The higher the value of an insulating oil's flashpoint (Flash Point), the better the insulating oil's resistance to the flashpoint (Flash Point) and hence the oil's non-flammability. ${ }^{\circ} \mathrm{C}$ is the unit of measurement for this test result (degrees Celsius). The IEC 60422 and ASTM D93 standards were employed in the testing, and the test equipment used was the Pensky Martens Flash Point Tester, as shown in the Fig. 4.

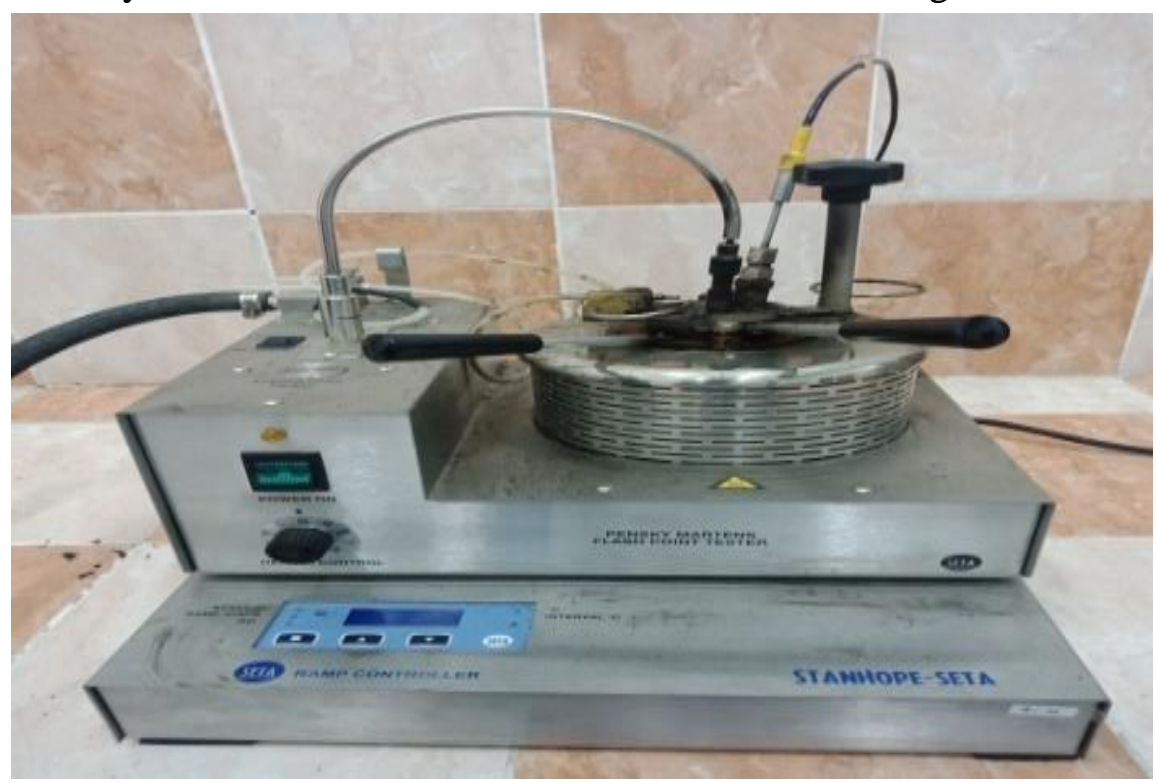

Fig. 4. Pensky martens flash point tester

\section{RESULTS AND DISCUSSION}

Some information was gathered for the study from the results of earlier testing. The following is the information gathered from the test results. Data breakdown voltage was utilizing a $12.7 \mathrm{~mm}$ ball electrode with a $2.5 \mathrm{~mm}$ gap between the electrodes. Data on the water content of each sample collected before and after oil temperature conditioning. Before and after oil temperature conditioning, each sample's viscosity was measured. Before and after oil temperature conditioning, data on flashpoints were gathered from each sample. Table 1 is presented value of breakdown voltage $(\mathrm{kV})$. 
https://doi.org/10.51630/ijes.v2i2.17

Table 1 Value of Breakdown Voltage $(\mathrm{kV})$

\begin{tabular}{ccccccc}
\hline & \multicolumn{5}{c}{ Breakthrough Voltage (kV) } \\
\cline { 2 - 7 } Test & $\begin{array}{c}\text { without } \\
\text { Conditioning }\end{array}$ & $30^{\circ} \mathrm{C}$ & $50^{\circ} \mathrm{C}$ & $70^{\circ} \mathrm{C}$ & $90^{\circ} \mathrm{C}$ & $110^{\circ} \mathrm{C}$ \\
\hline 1 xBdV & 14 & 18 & 23 & 28 & 35 & 40 \\
$2 x B d V$ & 11 & 15 & 21 & 26 & 33 & 38 \\
$3 x B d V$ & 9 & 14 & 20 & 25 & 30 & 36 \\
$4 x B d V$ & 8 & 11 & 20 & 23 & 28 & 36 \\
$5 x B d V$ & 8 & 10 & 18 & 22 & 26 & 34 \\
$6 x B d V$ & 7 & 10 & 18 & 22 & 26 & 33 \\
\hline
\end{tabular}

Fig. 5 shown the results of the Breakdown voltage test (Breakdown) of Virgin Coconut Oil (VCO) using a ball electrode type $12.7 \mathrm{~mm}$ with an interval of $2.5 \mathrm{~mm}$ may be seen to evaluate the data in table 1 in greater depth.

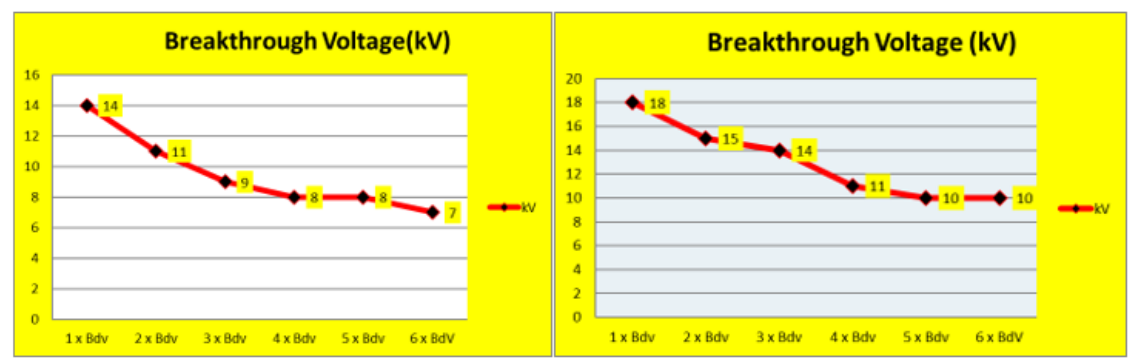

a. Unconditioned

b. Conditioning Temperature $30^{\circ}$

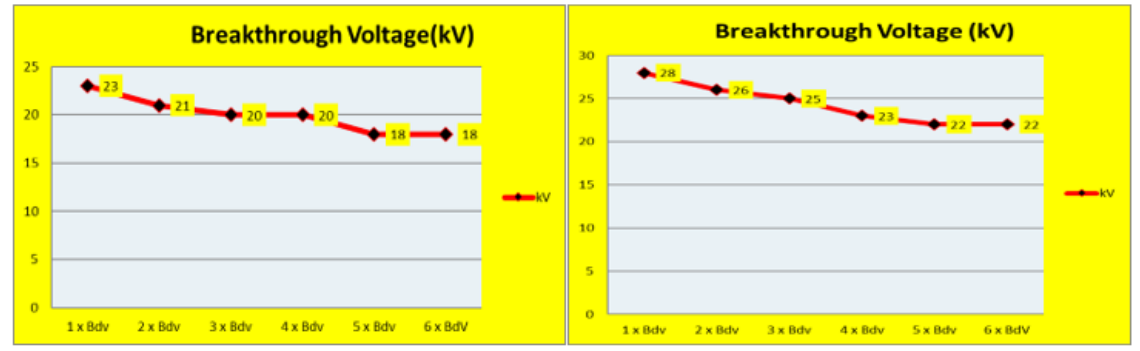

c. Conditioning Temperature $50^{\circ}$

d. Conditioning Temperature $70^{\circ}$

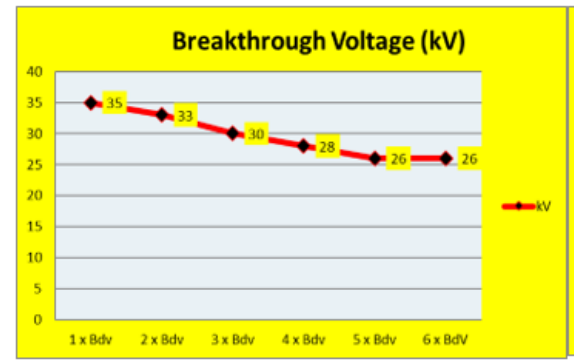

e. Conditioning Temperature $90^{\circ}$

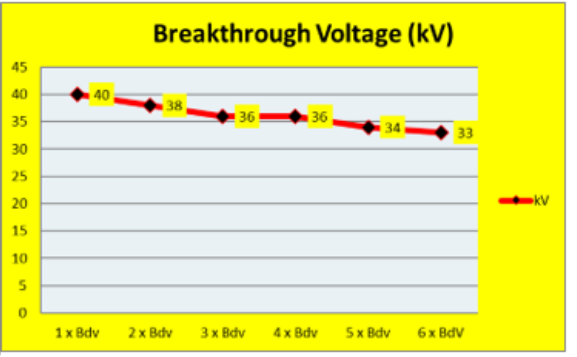

f. Conditioning Temperature $110^{\circ}$

Fig. 5. Breakthrough voltage graph at conditioning temperature

Fig. 6 show that when a breakdown voltage is applied, the breakdown voltage value tends to decrease. However, due to particles (dirt) being settled in the oil around the electrodes, as shown in Fig. 5 and 6, it causes breakdown voltage to accelerate. 


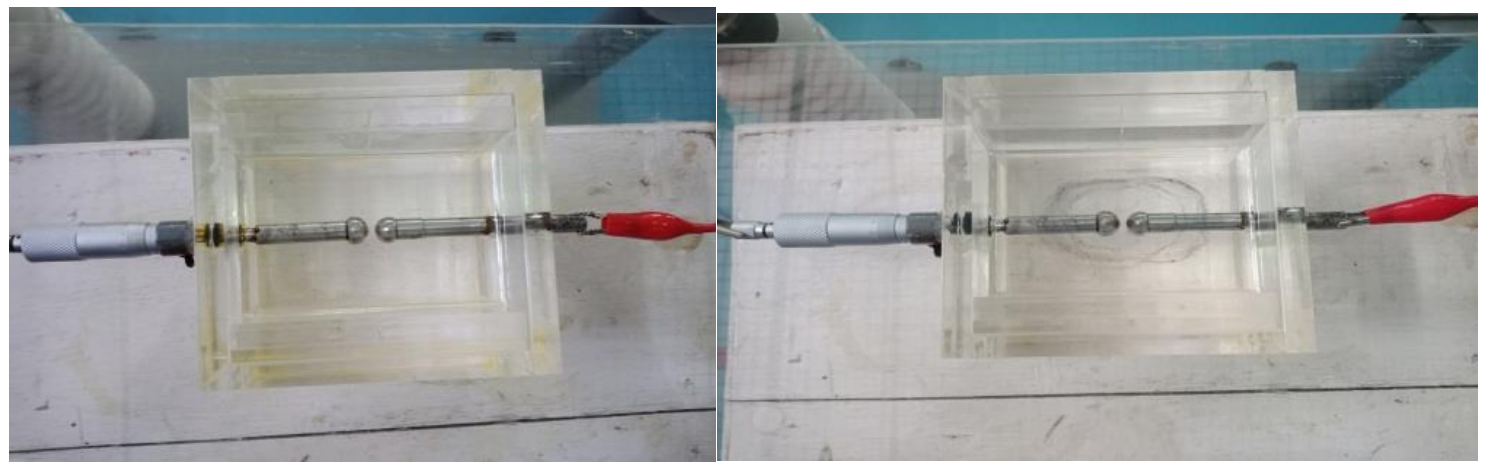

Before BdV

After BdV

Fig. 6. Breakdown voltage system

In theory, the stress on the insulation is a pull or pressure (stress) that the force must resist within the insulation to prevent penetration. The electrons are securely bonded to the molecule in the chemical structure of an insulating substance, and this bond resists the tension induced by the stress. If this bond is disrupted in one location, that location's insulating characteristics are lost. When a voltage is applied to an insulating material, electrons are transferred from one molecule to another, resulting in conduction or leakage currents.

\section{CONCLUSION}

Following several tests on Virgin Coconut Oil (VCO), which included determining the breakdown voltage at average temperatures and conditioning temperature variations, it was determined that the breakdown voltage value under normal conditions (without Conditioning) is only 46.67 percent of the breakdown voltage value. However, the breakdown voltage value can still be used as a comparison tool for the breakdown voltage value during Conditioning that meets or surpasses the IEC 156 standard's breakdown voltage value, namely $90^{\circ}$ with a breakdown voltage of $35 \mathrm{kV} / 2.5 \mathrm{~mm}$ and $110^{\circ}$ with a breakdown voltage of $40 \mathrm{kV} / 2.5 \mathrm{~mm}$.

\section{REFERENCES}

[1] B. S. H. M. S. Y. Matharage, M. A. R. M. Fernando, M. A. A. P. Bandara, and G. A. Jayantha, "Performance of Coconut Oil as an Alternative Transformer Liquid Insulation," vol. 20, no. 3, 2013.

[2] A. A. H. Zaidi, N. Hussin, and M. K. M. Jamil, "Experimentalstudy on vegetable oils properties for power transformer," 2015 IEEE Conf. Energy Conversion, CENCON 2015, pp. 349-353, 2015, doi: 10.1109/CENCON.2015.7409567

[3] D. Hinduja, Gayathri, C. S. Kalpage, and M. A. R. M. Fernando, "Laboratory investigation oftreated coconut oil as transformer liquid insulation," 2011 6th Int. Conf. Ind. Inf. Syst. ICIIS 2011 -Conf. Proc., pp. 108-113, 2011, doi: 10.1109/ICIINFS.2011.6038050

[4] Ansyori, Z. Nawawi, M. Abubakar Siddik, and I. Verdana, "Analysis of Dielectric Strength of Virgin Coconut Oil as an Alternative Transformer Liquid insulation," J. Phys. Conf. Ser., vol. 1198, no. 5, 2019, doi: 10.1088/1742-6596/1198/5/052003.

[5] R. Kurnianto, M. Taufan, Z. Nawawi, M. Nagao, and N. Hozumi, "Breakdown strength of biodegradable dielectric liquid: The effect of temperature and viscosity," 2012 22nd Australas. Univ. Power Eng. Conf. "Green Smart Grid Syst. AUPEC 2012, 2012

[6] M. Rafiq, D. Khan, and M. Ali, "Insulating properties of transformer oil-based silica 
nanofluids,” 2015 Power Gener. Syst. Renew. Energy Technol. PGSRET 2015, pp. 13, 2015, doi: 10.1109/PGSRET.2015.7312201.

[7] A. R. ARRAHMAN, "Pengaruh Suhu Dan Lama Pengeringan Kopra Terhadap Rendemen Minyak," 2018.

[8] D. K. Cahyaningrum, "Analysis of Characteristic Pre-Breakdown Voltage Phenomenon Based Experiment on Oil Insulation," pp. 1-51, 2017

[9] A. Merev and İ. Karaman, "Implementation and Analysis of a Reference Partial Discharge Measurement System," Mapan -J. Metrol. Soc. India, vol. 34, no. 1, pp. 43-48, 2019, doi: 10.1007/s12647-018-0296-y.

[10] Y. Du et al., "Effect of semiconductive nanoparticles on insulating performances of transformer oil," IEEE Trans. Dielectr. Electr. Insul., vol. 19, no. 3, pp. 770-776, 2012, doi: 10.1109/TDEI.2012.6215079 